\title{
Carrier mediated of toxic elements, Part (III) Permeability of Chromium using SLM containing TPPS/xylene and application of chromium in water samples
}

\author{
*N. El-Said, N. Abdel rahman and M.M.S. Ali \\ Hot Labs. and Waste Management Center, Atomic Energy Authority, P.O. 13759, Cairo, Egypt
}

\begin{abstract}
:
Extractive removal of chromium Cr (III) from chloride solutions was carried out using TPPS/xylene. The efficiency of this extractant was studied under various experimental conditions, such as concentration of the aqueous phase, concentration of TPPS and Cr (III) present in the initial aqueous feed. The DTPA as stripping phase, temperature and time of extraction was studied. The percentage of $\mathrm{Cr}$ (III) extraction decreases with the increase of temperature at varying concentration of TPPS. The interference of the $\mathrm{Cr}(\mathrm{VI}), \mathrm{Cr}(\mathrm{III})$ and chloride were examined at the optimized conditions. Under the optimum experimental conditions 98.6-99.9\% of $\mathrm{Cr}(\mathrm{III})$ was extracted in 30-50 min at O/A of 1 with the initial feed concentration of $0.5 \mathrm{~g} / \mathrm{L}$ of $\mathrm{Cr}$ (VI). The extracted Cr (III) was quantitatively stripped with 0.02M DTPA. The repeated transport experiments of SLM was shown and to reused in succeeding extraction of chromium (III). Finally a few experiments were performed with the water samples effluent from River Sea and lake. The repeated transport experiment of SLM was shown and the stability of SLM was described using the Danesi's thermodynamic model. The long-term integrity of SLM was found. Total chromium was determined after the reduction of $\mathrm{Cr}$ (VI) to Cr (III) by using ascorbic acid as reducing reagent. The proposed optimization has been applied to the speciation of chromium in natural water samples with satisfactory results.
\end{abstract}

Keywords: diffusion Facilitated transport; toxic elements; chromium Cr (III); TPPS/xylene; reaction mechanism, Transport modeling.

\section{Introduction}

Trace heavy metals are the major pollutants in the environment $\mathrm{Cr}$ (III). It has been widely recognized that the impact of detrimental heavy metals on the ecological system, biological organisms as well as human health not only depends on the total amount of the element, but also depends significantly on its chemical forms ${ }^{(1)}$. Chromium Cr (III) is a major pollutant for environment usually as a result of some industrial pollution including tanning factories, steel works, industrial electroplating, wood preservation and artificial fertilizers. Chromium species exist mainly in two different oxidation states in the environment $\mathrm{Cr}$ (III), and $\mathrm{Cr}$ (VI), which have contrasting physiological effects. $\mathrm{Cr}(\mathrm{III})$ is considered as an essential trace element for the maintenance of an effective glucose, lipid, and protein metabolism in mammals ${ }^{(2,3)}$. On the other hand, $\mathrm{Cr}(\mathrm{VI})$ can be toxic for biological systems ${ }^{(4,5)}$, and water-soluble $\mathrm{Cr}(\mathrm{VI})$ is extremely irritating and toxic to human body tissue owing to its oxidizing potential and easy permeating of biological membranes ${ }^{(6)}$.Therefore, it is of increasing importance to accurately define the individual quantity of both species in environmental and biological samples. A great number of speciation studies of chromium have been carried out in solid and liquid ${ }^{(7,8)}$ samples .Chromium is an element with muta-, terato- and carcinogenic properties ${ }^{(9-12)}$ present in some industrial wastewater ${ }^{(13-15)}$. Thus, removal of chromium due to economic and environment protection reasons is required. The application of the majority of conventional methods of removing chromium(III) from wastewater is connected with increase in large amounts of the sludge containing chromium, often in high concentration ${ }^{(6,7)}$. There is a problem with its reuse. The liquid membrane transport mediated with a mobile carrier has been proposed as a promising technology for separation and enrichment of various substances ${ }^{8-11)}$. A suitable mobile carrier provided selective and effective transport of specific ions through the membrane. There are a few papers ${ }^{(12-17)}$ about the facilitated transport of chromium (III) using a liquid membrane. Only a little attention has been paid to the pertraction of anionic forms of chromium (III) ${ }^{(18-21)}$. The most authors ${ }^{(22-25)}$ is focused on the pertraction of cationic forms of chromium (III). This form of chromium (III) is the more popular ${ }^{(26,27)}$. One of a big problem is to choose a right carrier for chromium (III) pertraction. The most carriers made stable molecules with transported chromium (III) ions ${ }^{(28,29)}$. Liquid membranes combine a single step extraction and stripping processes which are generally carried out in two separate steps in conventional solvent extraction processes. A one-step liquid membrane process provides the maximum driving force for the separation of a target species, leading to the best cleanup and recovery of the species ${ }^{(30)}$. The mass transfer mechanism for the target species to go from the feed solution to the strip solution is through facilitated ${ }^{(31-35)}$ transport Quinn and $\mathrm{Li}^{(5,6)}$ explained 
the facilitated transport mechanism through liquid membranes.

\section{Experimental}

TPPS 99\%, from Aldrich, chromium chloride nitrate, 99\% from Merck. Other chemicals are analytical grade from Fluka Scientific. All chemicals and reagents used were of AR graded. The UV-VIS spectrum of the prepared solutions was determined using a Shimadzu UV-VIS recording spectrophotometer type UV-160 A. $\mathrm{Cr}$ (III) in $0.1 \mathrm{M} \mathrm{HCl}$ was measured at $\lambda=470 \mathrm{~nm}$, while $\mathrm{Cr}(\mathrm{III})$ in $0.1 \mathrm{M} \mathrm{HCl}$ at $\lambda=412 \mathrm{~nm}$ using change in color method [10]. An apparatus for membrane extraction in Fig. 1 was composed of two compartments vessels made of Teflon and Plexiglass and arranged both coaxially and horizontally. The liquid membrane was fixed on Sartorius SM cellulose nitrate micro porous carrier (thickness $65 \sim \mathrm{m}$, diameter of pores $0.2 \sim \mathrm{m}$, porosity $70 \%$, effective area $6.25 \mathrm{~cm}^{2}$ ) and placed at the bottom of the inner vessel.

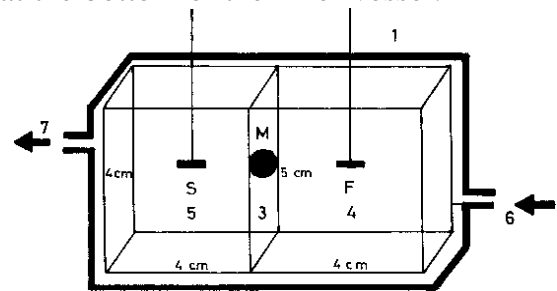

Fig.1.Scheme for pertraction apparatus. (1) Double shield glass outer vessel; (2) Teflon cross-stirring blade; (3) supported membrane (cellulose nitrate); (4) feed compartment; (5) strip compartment; (6) input (cell double jacket); (7) output.

The carrier was washed with acetone and dried for degradation of emulsion globules which cover the SM pores (regeneration), then saturated with the membrane phase. The volumes of the solutions were placed in the outer (feed phase, F) and inner (receiving phase, S). On the basis of numerous experiments at various stirring rates, stirring rate of $150 \mathrm{rpm}$ in the counter-current mode, using a cross-shaped Teflon stirrer was found to be optimal. The distance of stirrer from the membrane was fixed at about $3 \mathrm{~mm}$, the level of both phases were the same and small volumes of both phases were taken out at various time intervals for measuring concentration. Unless otherwise stated, experiments were performed. The calculated species confirmed by the speciation in Fig.2.

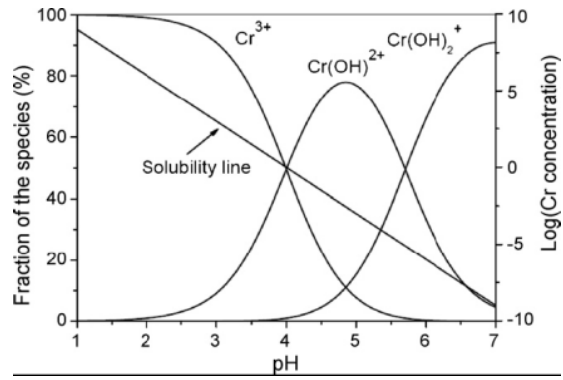

Fig.2. Solubility limit of $\mathrm{CrCl}_{3}$ and distribution of the chromium species as a function of $\mathrm{pH}$ solution.

\subsection{Permeation model of $\mathrm{Cr}$ (III) across the supported liquid membrane SLM}

The mass transfer of $\mathrm{Cr}$ (III), across the membrane is described by considering only diffusional parameters. The interfacial flux due to the chemical reaction is neglected, as the chemical reactions seem to take place at the interface aqueous source solution-membrane and membrane-receiving aqueous solution interfaces, and different studies suggest that chemical reactions can be considered as occurring instantaneously relative to the diffusion process. Therefore, to model the mass transfer of $\mathrm{Cr}$ (III), it is necessary to consider diffusion of the solute through the aqueous source boundary layer, the reversible chemical reaction at the interface and diffusion of the metal complex species in the membrane. Membrane permeabilites were determined by monitoring metal on centration UV-Perkin Elmer 1100B spectrophotometer in the source phase as a function of time. The permeation coefficient $P$ was computed by:

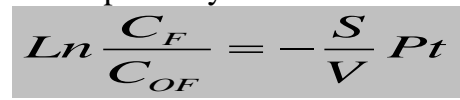

Where $V$ is the volume of the source phase solution $\mathrm{cm}^{3}, S$ is the effective membrane area $\mathrm{cm}^{2}, C_{F}$ and $C_{O F}$ are the concentrations of metal ions in the source phase at a given time $t$ and zero, respectively $\mathrm{mol} / \mathrm{L}$ and $t$ the elapsed time s.

\subsubsection{Extraction equilibrium}


Data shows the $\mathrm{Cr}$ (III) extraction from $0.1 \mathrm{M} \mathrm{HCl}$ solutions by TPPS dissolved in xylene have been obtained elsewhere w10x; however, the value of the extraction constant was not calculated. Thus, in the present work, these experimental data were analyzed numerically with the Mintique in order to further determine the stoichiometry of the species formed as well as the corresponding extraction constant value. The program is based on minimization of the error-square sum:

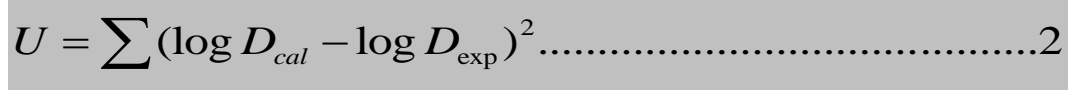

Where $D_{\text {exp }}$ are the experimental values of the distribution coefficient and $D_{c a l}$ are the corresponding calculated values from the relevant mass balance equation for a proposed model. Results obtained from the numerical treatment showed that the extraction of $\mathrm{Cr}(\mathrm{III})$ by TPPS/xylene is best represented by:

$$
\mathrm{H}_{\text {aq }}^{+}+\mathrm{Cr}(\mathrm{OH})_{2} \mathrm{Cl}_{2}^{-}+2 \mathrm{~L}_{\text {org }} \mathrm{Z} \quad \mathrm{HCr}(\mathrm{OH})_{2} \mathrm{Cl}_{2}^{-} \cdot \mathrm{L}_{2} \text { org } \ldots \ldots \ldots \ldots \ldots \ldots \ldots \ldots \ldots \ldots \ldots \ldots \ldots \ldots \ldots \ldots . .3
$$

Where $\mathrm{L}$ is represents the ligand. The value of $K E q u .4$. for extraction in the above reaction $3,0.1 \mathrm{M} \mathrm{HCl}$ is $2.4 \times 10^{-5}$ with St.error equal 0.005 . And St.dev equal 0.002 .

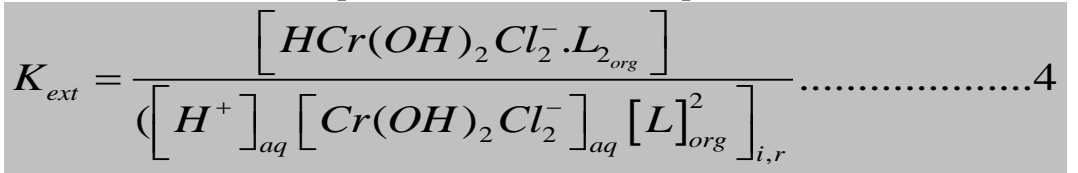

The reaction mechanism was shown in Fig.3.

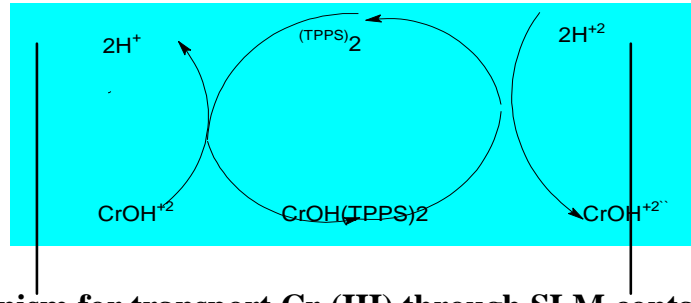

Fig.3. Suggested mechanism for transport $\mathrm{Cr}$ (III) through SLM containing TPPS as a carrier.

\subsubsection{Permeation model.}

The $\mathrm{Cr}$ (III) transport rate is determined by the rate of diffusion of $\mathrm{Cr}$ (III).Containing species through the source diffusion layer and the rate of diffusion of $\mathrm{HCr}(\mathrm{OH})_{2} \mathrm{Cl}_{2}^{-}$through the membrane. Then, the flux of $\mathrm{Cr}$ (III) crossing the membrane may be derived by applying Fick's first diffusion law to the diffusion layer on the source side, and to the membrane. The diffusional fluxes and the source aqueous boundary layer $J$ and at the membrane $J$ can be expressed as org. by the following equations:

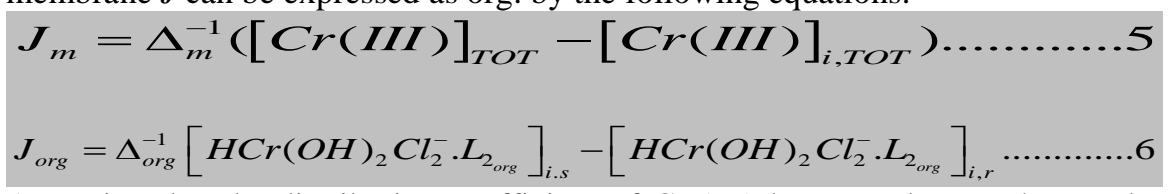

Assuming that the distribution coefficient of $\mathrm{Cr}$ (III) between the membrane phase and the receiving phase is much lower than that between the source phase and the membrane, the concentration of the $\mathrm{Cr}$ (III)-extracted complex in the membrane phase on the receiving solution side may be negligible compared with that on the source solution side.

Then, Eq.6,7. can be re-written as:

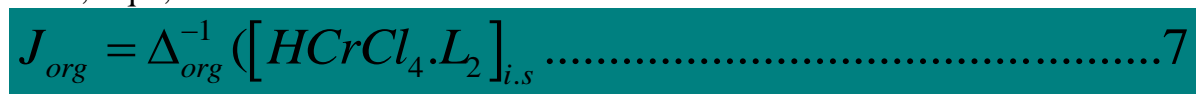

If the chemical reaction expressed by reaction.3. is assumed to be fast compared to the diffusion rate, local equilibrium at the interface is reached and concentrations at the interface are related through the expression:

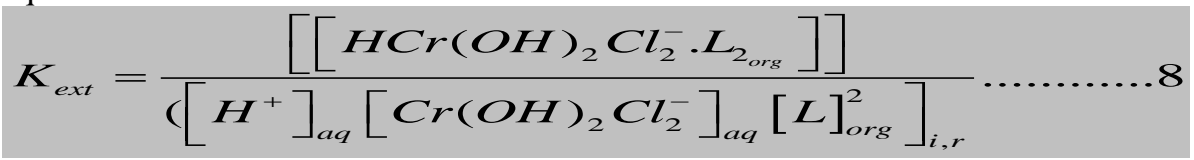

At the steady state, $J_{s}=J_{\text {org }}=J$ and by combination of Eqs.5, 7 and 8 the following expression is obtained:

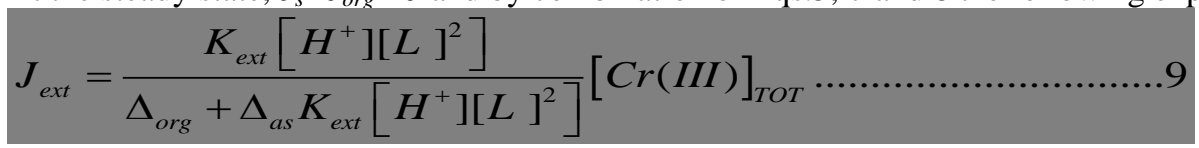


The permeability coefficient can be defined as:

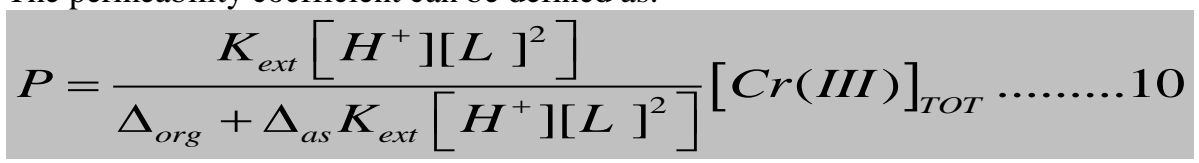

\subsubsection{Effect of carrier (TPPS) concentration}

According to the above results, a composition of $0.01 \mathrm{M} \mathrm{Cr}$ (III) in $0.3 \mathrm{M} \mathrm{NaCl}, \mathrm{pH} \sim 3$ for the feed solution was chosen. Unless otherwise stated, the composition of strip solution remained at $0.02 \mathrm{M} \mathrm{DTPA}, 0.1 \mathrm{M} \mathrm{NaCl}$, and $\mathrm{pH} 4-5$. Fig.4. depicts the effect of membrane concentration on the extraction of $\mathrm{Cr}$ (III). It shows the transport kinetics in terms of $\ln \left(C_{\mathrm{F}} / C_{\mathrm{OF}}\right)$ versus time curves. It was noticed that there is no deviation from linearity in the pertraction process. It is obvious that moderate increase in TPPS concentration, leads to an increase in initial flux of the metal through the membrane and exhibits a maximum at $0.1 \mathrm{M}$ TPPS. While the value of distribution ratio continues to increase progressively. For instance, by changing the TPPS concentration from 0.1 to $0.3 \mathrm{M}$, the distribution ratio of $\mathrm{Cr}$ (III) was increased by 40 times. The calculated values of the effective permeability coefficients for the extracted complex of $\mathrm{Cr}(\mathrm{III})$ in the membrane lie in a relatively wide interval, as shown in Fig 8. Shows the permeability coefficients of the metal investigated through SLM calculated from the slopes of the linear parts of the $\ln \left(C_{\mathrm{F}} / C_{0 \mathrm{~F}}\right)$ versus time plot. It is clear that, there is an effective increase of permeability coefficient upon increasing cyanex concentration from 0.1 to $0.3 \mathrm{M}$ in membrane phase. The permeability coefficient of Cr (III) increased as TPPS concentration increased from 0.1 to $0.3 \mathrm{M}$ membrane concentration, due to higher distribution coefficient with increasing TPPS concentration in the membrane phase. This is probably due to the potential gradient of $\mathrm{pH}$ 's between the feed and the strip. Steady increase of permeability coefficients is observed upon increasing TPPS concentrations from 0.1 to $0.3 \mathrm{M}$ TPPS. After $0.5 \mathrm{~h}$ pertraction, the metal yield in the strip was $45 \%$ with further increase upon increasing time. This equilibrium state was achieved after $1 \mathrm{~h}$ for $0.3 \mathrm{M}$ TPPS, this linearity occurs after about $2 \mathrm{~h}$ pertraction. After $0.5 \mathrm{~h}$ of pertraction, about $45 \%$ of initial amount of $\mathrm{Cr}$ (III) were accumulated in the stripping phase. But the transport of $\mathrm{Cr}$ (III) appeared to be stopped after $1 \mathrm{~h}$ pertraction with $85 \%$ yield in the strip phase which may be due to membrane stability and linear concentration gradient resulting in equilibrium between feed and strip, this fact is confirmed by the significant a small decrease of $\mathrm{pH}$ of the stripping phase.

\subsubsection{Influence of $\mathrm{pH}$ of feed.}

Effect of the feed solution acidity at varying $\mathrm{pH} 1-4$ on the transport of $\mathrm{Cr}(\mathrm{III})$ was studied. The initial metal concentration in the feed was $0.01 \mathrm{M}$ much lower than the carrier concentrations $(0.1 \mathrm{M})$. A solution of $0.02 \mathrm{M}$ DTPA was used as the stripping phase. The distribution of the chromium species as a function of solution $\mathrm{pH}$ are shown in Fig.5. Transport of $\mathrm{Cr}$ (III) in all systems investigated can be described by reaction mechanism Fig.3. In the time interval from 0.5 to $1 \mathrm{~h}$ and feed metal concentration $C_{\mathrm{FD}} 0.01 \mathrm{M}$, when $[\mathrm{HCL}]_{\mathrm{OF}} 0.1 \mathrm{M}$ and the feed acidity decreased to $2 \mathrm{pH}$, the nitric acid transport from the feed into the strip solution decreased. Shows the permeability coefficients of the metal of feed against permeability show fig(9). Consequently, the acid concentration gradient in the feed diffusion layer decreased due to the transport of $\mathrm{HCl}$ and caused an increase of $K_{\mathrm{dF}}$ of $\mathrm{Cr}$ (III). On the other hand, an increase in $K_{\mathrm{dS}} \mathrm{Cr}$ (III) can be demonstrated at pH 4-5, in consequence of increasing significance of the solvation mechanism. Both of these effects led to the decrease of $P_{\mathrm{F}}$ of $\mathrm{Cr}$ (III) at $[\mathrm{HCl}]_{\mathrm{F}} 0.1 \mathrm{M}$ where $K_{\mathrm{dS}}$ decreases rapidly with increasing $[\mathrm{HCl}]_{\mathrm{F}}$. From Fig. $(5,9)$. It is obvious that $\mathrm{P} \mathrm{Cr}$ (III) increases with decreasing $[\mathrm{HCl}]_{\mathrm{F}}$.

\section{.3.2. Influence of strip concentration}

Fig.(6), shows the influence of strip concentration from (0.005-0.02M DTPA). It is interesting to note that the effects of changing strip concentration on the transport of $\mathrm{Cr}$ (III) were different. With increasing strip concentration, from 0.005 to $0.02 \mathrm{M}$ DTPA the transport of the permeability of $\mathrm{Cr}(\mathrm{III})$ increased Fig.6, with no deviation from linearity upon further increase, from 0.005 to $0.02 \mathrm{M}$ DTPA. This may be due to the low transport of $\mathrm{HCl}$ alone and the low transport of water from the phase with the higher value of thermodynamic activity into the other with the lower one that could occur in principle by an extraction mechanism. This is confirmed by low decreasing the measured $\mathrm{pH}$ values of strip phase after $2 \mathrm{~h}$ and longer time of pertraction. The ratio between transport rates of $\mathrm{HCl}$ acid and that of metal plays an important role, i.e. when the metal transport is faster, it is preferentially accumulated in the strip and the extraction efficiency is high. While, if the metal transport rate is slower than the acid transport rate, the acid is transported preferentially into the strip phase causing low extraction efficiency.

\subsubsection{Effect of temperature}

Fig(7).Shows that there is an increase in the permeability coefficient by increasing temperature up to $298 \mathrm{~K}$. 
At fixed stirring rate, the natural logarithm of the rate constant was found to be linear with respect to $1 / T$ (Fig.10), which allowed estimating the activation energy of the slope of the straight line according to the Arrhenius and Eyring equations. The activation energies from temperature range 278-298K for the studied system was calculated to be $65 \mathrm{k} \mathrm{cal} / \mathrm{mol}$ at our hydrodynamic conditions. The estimated activation energy falls in the suggestion that the transport of $\mathrm{Cr}$ (III) is likely controlled by chemical reaction controlled process.

\subsection{Membrane stability}

To characterize the SLM stability we applied the Danesi's thermodynamic model [35] following the procedure described by Hill et al., [36]. According to Hill et al., in repeated transport experiments, the decrease of permeability coefficients $P_{M}$ is the linear function of the runs number:

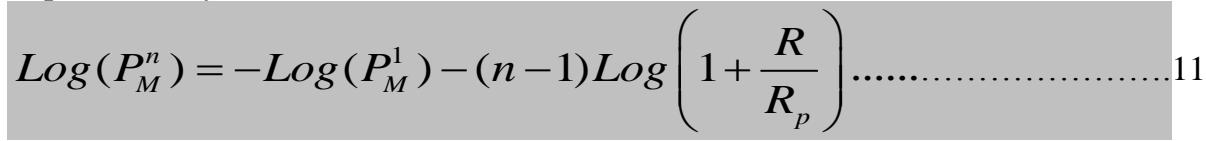

Where, $n$ is the number of experiments, $P_{M}^{n}$ and $P_{M}^{1}$ are the $\mathrm{HCr}_{\mathrm{O}^{-}}$permeability coefficients in the transport experiment and in the first run, respectively; $\mathrm{R}=\left(\mathrm{V}_{\text {source }}+\mathrm{V}_{\text {receiving }}\right) / \mathrm{V}_{\mathrm{SLM}}$ and $K p$ is the apparent distribution coefficient of the ion carrier between the SLM and both aqueous phases; $\mathrm{S}$ is the stoichiometry factor for ion carrier, i.e., TPPS. Using, the logarithmic variation for $P_{(n) \mathrm{M}}$ versus the runs number was prepared and it is shown in Fig(11).Describe the Modeling the membrane stability for extraction of $\mathrm{Cr}$ (III) from aqueous medium by TPPS as membrane and DPTA as stripping phase For $\mathrm{Cr}(\mathrm{OH})_{2}{ }^{+}$transport through SLM with TPPS, where $S$ $=1$ and $R=1000$ Eq. (6) was found as equal:

\section{$\log P_{(n M)}=(-6.0)-(n-1) 1 \log (1+(1000 / 10000))$.}

The observed high values of determination coefficient $\left(r^{2}=0.9885\right)$ proves that correlation is high significantly important. From this equation, the empirical value of distribution coefficient $K p$ for membrane system studied was estimated as equal to $37946.6 \pm 1045$. The $\log K p=5.2$ obtained from this value corresponds to $K_{\mathrm{p}}=50000$ of the xylene/Cl- extraction system. Regarding to equation (11)

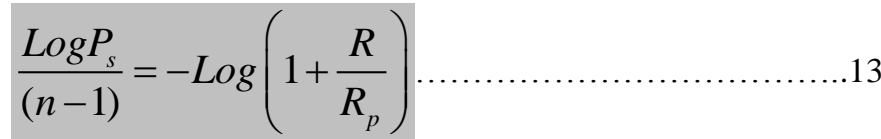

$\mathrm{P}_{\mathrm{S}}=\mathrm{P}_{\mathrm{n}} / \mathrm{P}_{\mathrm{o}}$ can be defined as membrane stability factor. To obtain a maximum membrane stability factor from this equation can be a chivied two conditions, one at $n=1$ or the second at $R_{P}=\infty$, therefore $0<R / R_{p}<1$, Taking in our consideration $\frac{\log P_{s}}{(n-1)}=\mathrm{K}$, where $\mathrm{K}$ is parameter of membrane degradation or instability factor resulting from calculation from the slope of plotting $\log P_{s}$ against $(n-1)$, Fig (11), The model of membrane stability was shown in Fig (11). The 3-D optimization was constructed in Figs 12, 13 and the contour in Fig.14. Taking in our consideration the mean value of $\log \mathrm{P}$ at $\mathrm{n}=1$ to 20 and $\log \mathrm{P}$ (mean value) is the membrane stability in the system under certain condition. To validate the feasibility of membrane stability statically evaluation can be considered. The standard deviation for single distribution ratio determination $(\Delta \mathrm{P})$ and the respective deviation for the average one $\left(\Delta \mathrm{P}^{\prime}\right)$ were calculated by applying the following equations;

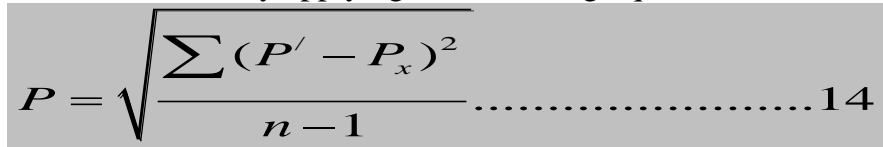

Where, $R_{X}$ stands do the fraction yield of pertraction $\mathrm{P}_{1}, \mathrm{P}_{2}, \ldots . \mathrm{P}_{20}$

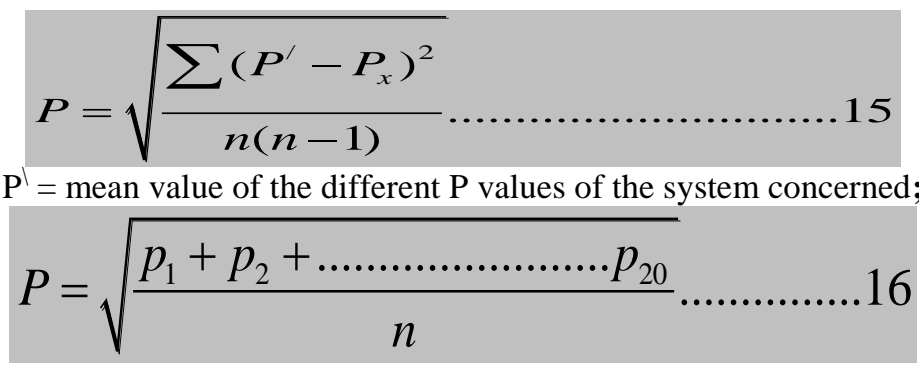

Where $\mathrm{n}$ is equals to 20 . The results obtained for the systems given values for the standard deviation for all the 
experiments concerned did not exceed $\pm 1.0 \%$ and the respective values for the average were less than $0.45 \%$. These results indicate satisfactory that the distribution results, which are the bases of the experimental work, are reproducible within the aforementioned error. It is to be mentioned that all the experiments in this thesis were performed in duplicate and some times in triplicate when is required.

\section{Conclusions}

The transport of $\mathrm{Cr}(\mathrm{III})$ using the TPPS under various experimental conditions has been studied and a mechanism of $\mathrm{Cr}$ (III) transport considering the aqueous film diffusion of metal ions, fast chemical reaction at the interface and diffusion of $\mathrm{Cr}(\mathrm{OH})^{+}$through the membrane is proposed. For concentrations of TPPS higher than $0.26 \mathrm{M}$, a limiting value of $23 \mathrm{mmrs}$ for permeability is obtained and the transport process is controlled by the diffusion in the aqueous stagnant film. Mass transfer coefficients in the membrane and in the aqueous phase are found to be 2.7 and $23 \mathrm{mmrs}$, respectively. Cr (III) can be selectively transported from DTPA solutions using a supported liquid membrane with TPPS over $\mathrm{Cr}$ (III). The transport of $\mathrm{Cr}$ (III) is enhanced using TPPS /xylene as a carrier if compared with other neutral organophosphorus TBP .

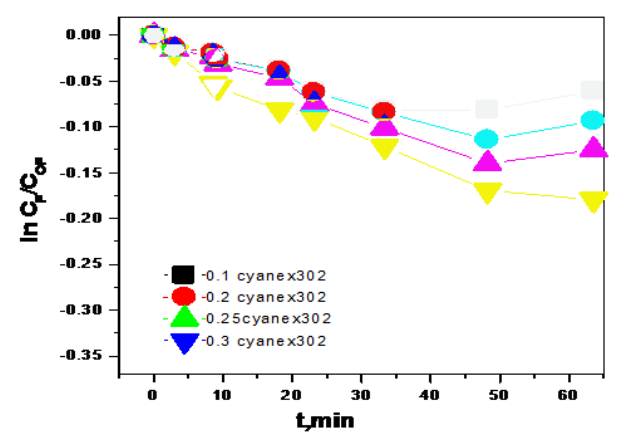

Fig 4: Similogarithemic plots of $\ln C_{F} / C_{0 F}$ against time, at different carriers concentrations.

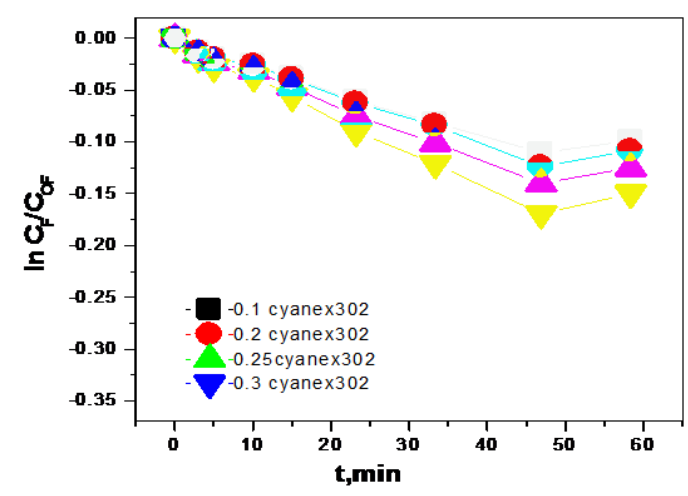

Fig. 5. Similogarithemic plot of $\ln C_{F} / C_{0 F}$ against time, min at different PHs concentrations.

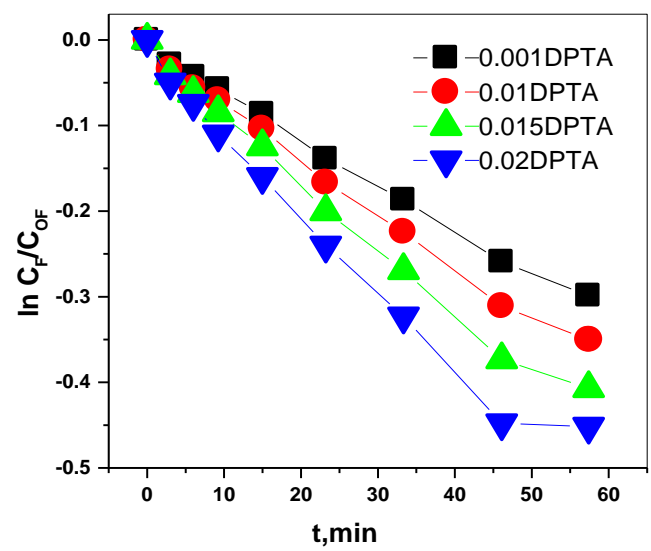


Fig 6: Similogarithemic plot of $\ln \left(\mathrm{C}_{\mathrm{F}} / \mathrm{C}_{\mathrm{OF}}\right)$ against time, min at different strip concentrations.

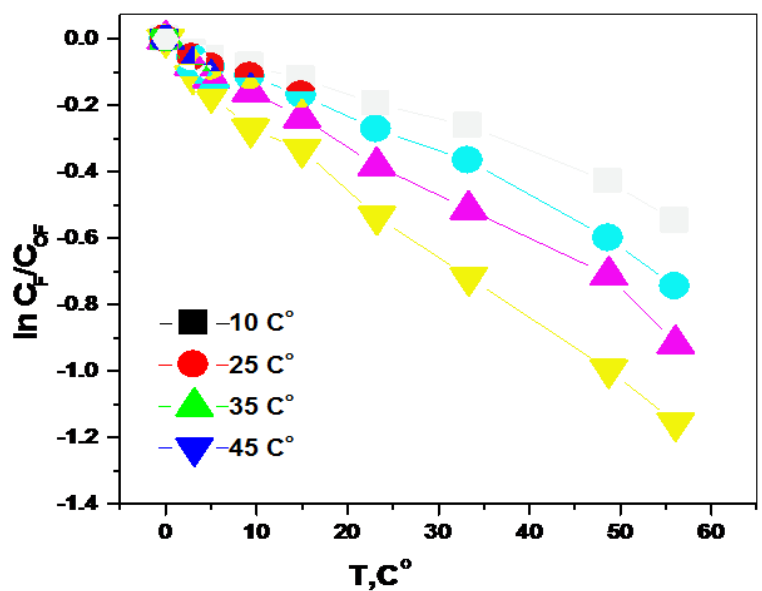

Fig. 7. Influence of temperature on permeability coefficient of $\mathrm{Cr}$ (III); F: 0.1M NaCl, 0.02M Cr (III), pH=4. 0.3M TPPS/xylene. S: 0.02M DTPA, 0.1M NaCl.

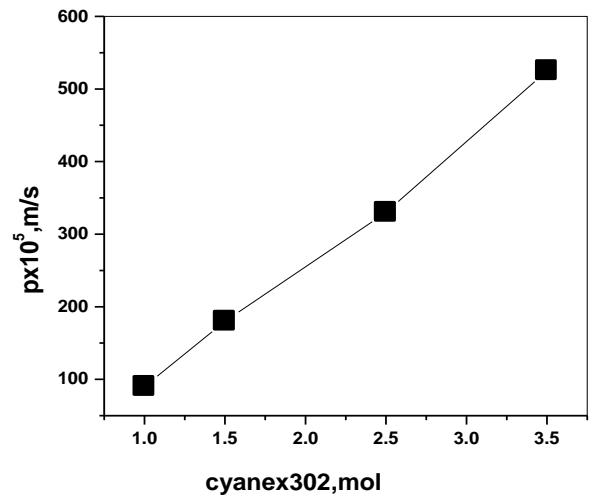

Fig.8. Influence of carrier concentration on permeability coefficient of $\mathrm{Cr}$ (III); F: 0.1M NaNO 3 , 0.02M Cr (III). M: x. TPPS/xylene.S:0.02M DTPA, $1 \mathrm{M}$ NaCl.

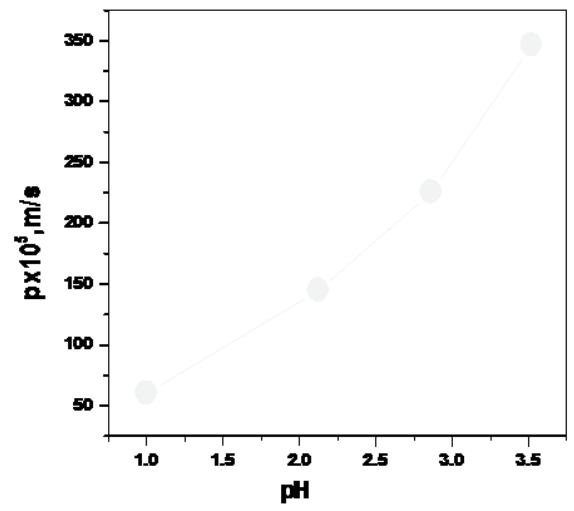

Fig.9. Influence of feed acidity on permeability coefficient of $\mathrm{Cr}$ (III); F:

0.1M NaNO, $0.02 M$ Cr (III). M: 0.1 TPPS/xylene.S:0.02M DTPA, 1M NaCl 


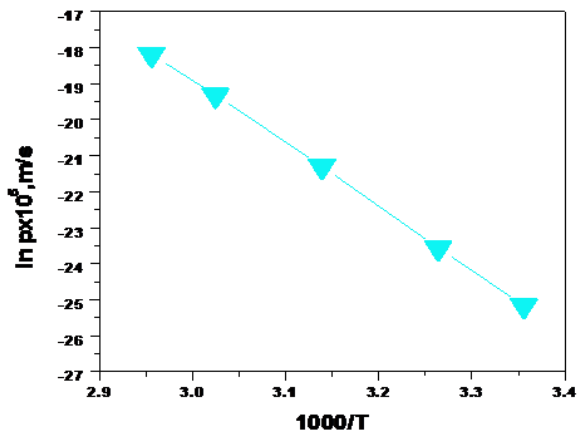

Fig.10.Influence of temperature on permeability coefficient as Linear plot of Arrhenius and Eyring for $\mathrm{Cr}$ (III); F: 0.1M NaCl, 0.02M Cr (III), pH=4. 0.3M

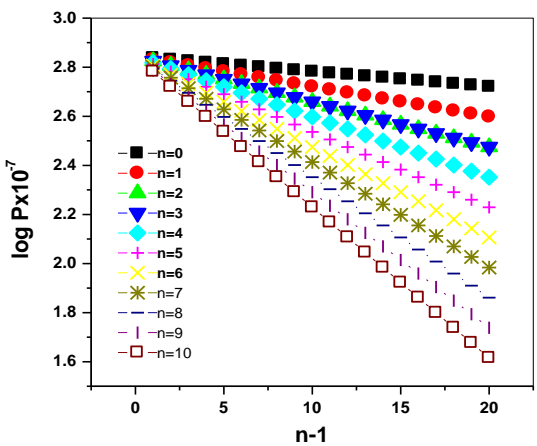

Fig.11.Modeling the membrane stability for extraction of $\mathrm{Cr}$ (III) from Aqueous medium by TPPS as membrane and DPTA as stripping phase TPPS/xylene. S: 0.02M DTPA,

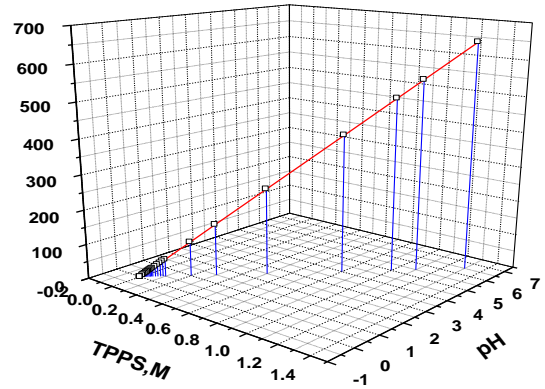

Fig.12.3-D plot model.a 


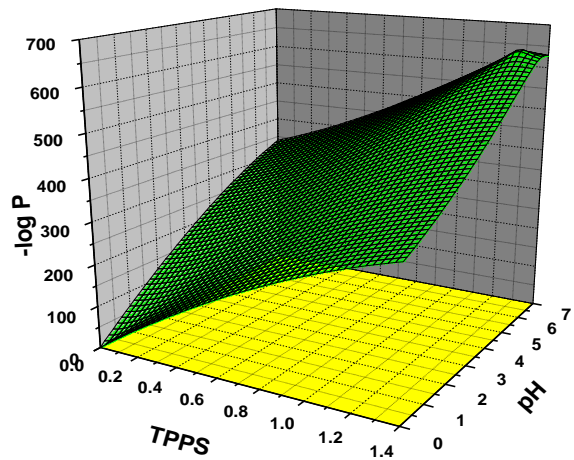

Fig.13.3-D plot for the model, b

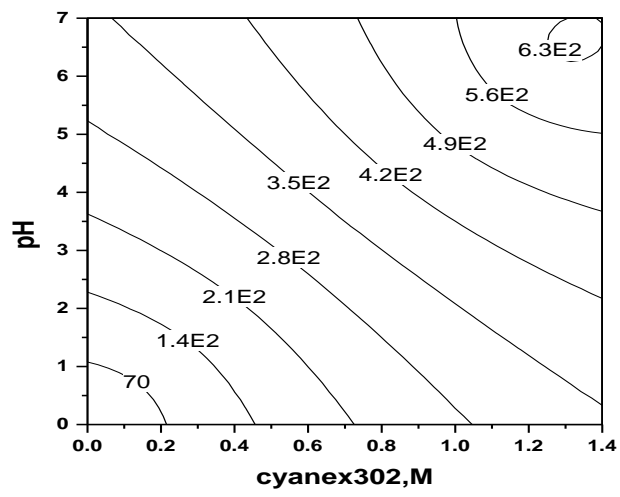

\section{Fig.14.3-D contour plot for the model}

\section{References}

[1]- $\quad$ A. Kot, J. Namiesnik, J.of, Trends Anal.Chem. 19 (2000) 69-79.

[2]- A.S. Prasad, D. Oberleas, J.Academic Press, 1976, pp. 79

[3]- J. Kotas, Z. Stasicka, J. Pollut. 107 (2000) 263-283.

[4]- A.K. Shanker, C. Cervantes, H. Loza-Tavera, S. Avudainayagam,J. Int. 31 (2005) 739-753.

[5]- A. Zhitkovich, J, Chem. Res. Toxicol. 18 (2005) 3-11.

[6]- P.M. Outridge, A.M. Scheuhammer, J. Contam. Toxicol. 130 (1993) 31-37.

[7]- M.J. Marques, A. Salvador, A.E. Morales-Rubio, J. Anal. Chem. 362 (1998) 239-248.

[8]- M.J. Marques, A. Salvador, A.E. Morales-Rubio, J. Anal. Chem. 367 (2000) 601-613.

[9]- T.J. O’Brien, S. Ceryah, S.R. Paterino, J, Mutat. Res. 533 (2003) 3.

[10]- K.C. Tagliari, V.M. Vargos, K. Zimiani, R. Cecchini, J, Toxicol. Pharmacol. 17 (2004) 149

[11]- R.'Swietlik, Publishing House of Radom university of Technology, Radom, 2001.

[12]- A. Molik, J. Siepak, R.' 'Swietlik, J. Dojlido, J. Stud. 13 (2002) 311

[13]- J.Bernhart, J. toxicol.Pharmacol. 26 (1997) 3

[14]- S.E. Kentish, G.W. Stevens, J, Chem. Eng. J. 84 (2001) 149.

[15]- Z. Kowalski, M. Konopka, J. Chemia in zynieria ekologiczna 9 (7) (2002) 707.

[16]- D. He, M. Ma, Z. Zhao, J. Membr. Sci. 169 (2000)53.

[17]- M. Eijiro, M. Tatsuo, K. Noriho, G. Masahiro, J. Biosci. Bioeng. 96 (2003) 370

[18]- J.S. Gill, H. Singh, C.K. Gupta, J. Hydrometallurgy 55 (2000) 113.

[19]- F. Valenzuela, C. Fonseca, C. Basualto, O. Correa, C. Tapia, J. Sapag:,J, Min. Eng. 18 (2005) 33.

[20]- B. Wionczyk, W. Apostoluk, J. Hydrometallurgy 72 (2004) 185.

[21]- B. Wionczyk, W. Apostoluk, J. Hydrometallurgy 72 (2004) 195.

[22]- R. Molinari, E. Drioli, G. Pantano, J. Technol. 24 (12-13) (1989) 1015.

[23]- A.M. Chaudry, S. Ahmad, M.T. Malik, J. Waste Manage. 17 (4) (1997) 211.

[24]- J. G. ega, W.Walkowiak, J. Appl. Chem., XLIII (3-4) (1999) 147.

[25]- R. Gawrónski, P. Religa, J. Monogr. PAN 22 (2004) 295.

[26]- J.R. Kramer, H.E. Allen, , Lewis, Chelsea, USA, 1988.

[27]- S. Kocaoba, G. Akcin, J. Talanta 57 (2002) 23.

[28]- M.D. Lanagan, D.C. Ibana, J. Min. Eng. 16 (2003) 237.

[29]- W.S. HO, K.K. Sirkar, Membrane Handbook, Chapman and Hall, Eds, New York, 1992.

[30]- N. Li, Norman, patent, 410,794.119. Assinee (1968).

[31]- N.C.Otto, J.A. Quinn, J. Chem. Eng. Sci. 26 (1971) 949-961.

[32]- D.R. Smith 1, R.J. Lander, J.A., J. Sep. Sci. 3 (1977) 225-241.

[33]- E.S. Matuleviclus, N.N. Li,, J.Sep. Purif. Methods 4 (1975) 73-96.

[34]- N.N. Li, , J. Membr. Sci. 3 (1978)265-269.

[35]- P.R. Danesi, L. Reichley-Vinger and P.G. Rickert, J. Membrane Sci., 3 I (1987) 117-145.

[36]- C. Hill, Journal of Membrane Science 114 (1996) 73-80

[37] - P. K. Parhi, Journal of ChemistryVolume 2013 (2013), Article ID 618236, 11 pages 